\title{
Populismo, polarização política e a pandemia do coronavirus: Donald Trump e a opinião pública nos Estados Unidos
}

\section{Populism, political polarization and the coronavirus pandemic: Donald Trump and public opinion in the United States}

\section{Jennifer Azambuja de Morais \\ Andressa Liegi Vieira Costa \\ Ana Julia Bonzanini Bernardi}

\section{Resumo}

O enfrentamento à pandemia da Covid-19 não está somente em medidas como o isolamento social e investimento massivo na saúde pública, mas também no combate a notícias falsas e discursos que minimizam a seriedade da doença. Nos EUA, o discurso populista do presidente Donald Trump, que muitas vezes contraria as recomendaçôes da Organização Mundial da Saúde, pode estar refletindo nas estatísticas da doença, visto que é o país com os maiores números de contaminados e de mortes. Sabendo que uma das principais consequências do discurso populista é a polarizaçáo de opiniôes, este artigo tem como objetivo verificar a formação da opinião pública sobre a Covid-19 nos EUA a partir dos posicionamentos de Trump. Parte-se da hipótese de que a polarização gerada pelo populismo de direita do presidente está afetando a forma como as pessoas reagem às medidas de restrição, criando opinióes divergentes sobre a gravidade do novo coronavírus. Os dados analisados demonstram uma polarizaçáo mais do que política entre os dois grupos, tendo efeitos sobre como os dois grupos percebem a pandemia de Covid-19.

\section{Palavras-chave}

Covid-19; Opiniáo Pública; Polarização Política; Discurso Populista; EUA.

\begin{abstract}
Fighting the Covid-19 pandemic does not solely rely on measures like social isolation and massive investments on public health, but also lies on combating fake news and discourses that downplay its seriousness. In the USA, the populist discourse of President Donald Trump, which frequently defies the World Health Organization's recommendations, might be reflected on the statistics of the disease, given that the country shows the highest numbers of infected and deaths. Knowing that one of the main consequences of populist discourses is the polarization of opinions, this paper aims to verify the formation of public opinion regarding Covid-19 in the USA through Trump's discourses. We depart from the hypothesis that the polarization created by the President's rightwing populism is affecting the way people react to the restriction measures, by generating opposing opinions regarding the seriousness of the new coronavirus. The data analyzed suggests a polarization beyond the political level, affecting the way both groups experience the Covid-19 pandemic.
\end{abstract}

\section{Keywords}

Covid-19; Public Opinion; Political Polarization; Populist Discourse; USA. 


\section{Introdução}

O mundo está enfrentando uma pandemia com a Covid-19, consequência do novo coronavírus, o SARS-COV-2. Mas esta não é a primeira pandemia mundial da história da humanidade ${ }^{1}$, a diferença é o advento da internet e das redes sociais, que estão permitindo um grande fluxo de informaçóes instantâneas ${ }^{2}$ sobre a doença. Os impactos são diversos, não somente nos sistemas de saúde, saneamento e segurança, como também na política, na economia e na cultura. Não é possível prever quando e como terminará esta crise da saúde mundial, mas é essencial afirmar que os impactos socioeconômicos estáo sendo nocivos à sociedade, pois a Covid-19 está denunciando o aumento das desigualdades sociais, agravando a crise econômica, que já estava em percurso, e deflagrando uma polarização política na sociedade.

No mapa de dados da Organizaçáo Mundial da Saúde (OMS) sobre a disseminação da doença, os Estados Unidos da América (EUA) estão no topo da lista, apresentando os maiores números de contaminados e de mortes pela Covid-19, conforme dados no site da OMS em 12 de novembro de 2020 (OMS, 2020). Além dessa preocupante estatística, o país parece não enfrentar somente a pandemia, como também uma onda de descrença na seriedade da doença, o que agrava mais a situação. Os discursos do presidente Donald Trump, desde as primeiras notícias sobre o cononavírus SARS-COV-2, têm minimizado a seriedade da doença, contrariado as recomendaçóes da OMS e da comunidade científica e politizado a crise enfrentada pela pandemia, polarizando ainda mais as opinióes públicas no país. Além disso, o presidente dos EUA recomenda fortemente o uso de medicamentos cuja eficácia para o tratamento da COVID-19 não tem comprovação científica. Antes da pandemia, os discursos de Trump já eram caracterizados como populistas e de direita, conforme Maly (2019), visto que têm apelo à intolerância, ao inimigo da sociedade e à defesa do nacional.

Sabe-se que a crise é mundial, mas o combate ao vírus depende das decisóes políticas de cada governante, o que, no caso dos EUA, pode estar gerando mais um combate: contra os discursos populistas, que podem estar contribuindo para efeitos

\footnotetext{
${ }^{1}$ A população já enfrentou a peste bubônica, a varíola, a cólera, a gripe espanhola e a gripe suína (H1N1) (REZENDE, 2009; COSTA e MERCHAN-HAMANN, 2016).

${ }^{2}$ Este excesso de informaçóes sobre o surto da Covid-19 seria uma "infodemia" (LIMA, LOPES e BRITO, 2020), declarada pela Organização Mundial de Saúde como um excesso de informaçóes sobre a pandemia, bem como uma "desinfodemia" (UNESCO, 2020), compreendida como o excesso de notícias falsas sobre o novo coronavírus.
} 
nocivos na sociedade, em especial nas parcelas mais vulneráveis. Neste sentido, o nosso objetivo é verificar a formação da opinião pública sobre a Covid-19 nos EUA frente aos posicionamentos de Donald Trump, especialmente à luz da polarização política encontrada nos EUA entre republicanos e democratas, que vai muito além do aspecto político, impactando inclusive na forma com que cada cidadáo está lidando com o isolamento social, com a desinformação e com a avaliação das medidas de controle e prevenção da Covid-19.

A hipótese proposta é de que a polarização gerada pelo populismo de direita do presidente está afetando as medidas de isolamento, criando opiniōes divergentes sobre a gravidade do novo coronavírus e ampliando as diferenças, para além do espectro político, entre republicanos e democratas. Para testar esta hipótese, utilizamos dados das pesquisas de opiniáo pública coletadas pelo Pew Research Institute nos meses de março, abril e setembro de 2020.

O artigo está dividido em três partes, além da introdução e conclusão. Primeiramente tratamos sobre populismo, discursos populistas e o seu impacto na polarizaçáo política. A seguir, analisamos a trajetória de Donald Trump durante a pandemia do coronavírus, seus discursos e a politização das medidas de contenção do vírus. Na sequência, analisamos os dados da opiniáo pública a partir de cruzamentos que levam em consideração a posição política dos respondentes - se democrata/ou com tendência ao partido Democrata ou se republicano/ou com tendência ao partido Republicano - e suas visôes sobre a pandemia, avaliaçóes do governo e adesão às medidas de isolamento social. Por fim, trazemos algumas consideraçóes finais, além de propostas de estudos futuros.

\section{Discursos populistas e polarização politica}

O termo populismo não é novo e é carregado de significados e avaliaçóes, o que o torna complexo, como pode-se ver nos clássicos de Germani ([1965] 1973), Di Tella ([1965] 1973), Ianni (1973) e Weffort (1978). Destaca-se que tais estudos analisam países da América Latina, mas indicam a possibilidade do surgimento do populismo em outros países. Germani ([1965] 1973), mesmo não trazendo o termo populismo, que já fazia parte da linguagem política da época, ressalta que a manipulação das classes populares pela elite era feita a partir de uma ideologia industrializante, com características de autoritarismo, nacionalismo, coletivismo e capitalismo.

Trazendo o debate mais para a atualidade, Laclau (2005) destacou que o populismo pode ser um modo de construir o político, ao invés de ser pensado apenas 
como uma ideologia, considerada como uma anomalia, em relação à democracia representativa. Enquanto um padrão discursivo ele pode criar polaridades e dicotomias, criar afetos e exaltar o espontâneo.

Este discurso constrói uma identidade popular que necessita da polarização, a partir da criação do "inimigo". Segundo Laclau (2005), a lógica do populismo é a circulação de uma identidade coletiva que é forjada pelo discurso e divisão dicotômica da sociedade em dois campos. Além disso, Mudde (2007) reforça que o populismo representa uma forma de política baseada em uma oposição moral entre as pessoas virtuosas e uma elite fundamentalmente corrupta.

$\mathrm{Na}$ literatura, os esforços em definir o populismo foram retomados com esta onda de governos populistas pelo mundo (MUDDE e ROVIRA KALTWASSER, 2017; HAWKINS e ROVIRA KALTWASSER, 2019; NORRIS e INGLEHART, 2019, entre outros). Como alguns exemplos tem-se Donald Trump nos EUA, Andrés Manuel López Obrador no México e Jair Bolsonaro no Brasil (TAMAKI e FUKS, 2020). Destaca-se que o populismo surge como uma interface mascarada que garante uma certa cumplicidade entre as intençóes e interesses dos políticos, tanto privados quanto coletivos, e os interesses de grupos eleitorais privados. Além disso, mesmo que o populista tenha uma crença genuína, o efeito do discurso populista se dá pela manipulação, pois tanto o governante quanto os governados distorcem, amplificam, mascaram ou matizam a realidade dependendo de seus interesses.

Para compreender melhor o populismo, destaca-se alguns elementos apontados pela literatura: "apelo ao povo" (LACLAU, 2005; STAVRAKAKIS e KATSAMBEKIS, 2014); antipolíticos, antielitistas e ideologias antiestablishment (MUDDE e ROVIRA KALTWASSER, 2017); um "discurso" caracterizado por um etos beligerante, com linguagem simples para gerar a sensação de proximidade entre os líderes e seus públicos, que já estão politicamente desencantados (JAGERS e WALGRAVE, 2007); um foco na "liderança", que geralmente é carismática, mas também intolerante e narcisista, e na "agência" partidária para popularizar e legitimar questóes populistas (VAN KESSEL, 2011); a exploração de crises de representação democrática, a tentativa de contornar as instituiçôes da democracia e a promoção de formas vagas de democracia direta para ganhar posiçóes de poder (TAGGART, 2002); clientelismo e paternalismo, especialmente na América Latina (PHILIP e PANIZZA, 2011); e uma relação complexa e turbulenta com a mídia (MAZZOLENI, 2003). 
Além desses elementos, estudos recentes têm apontado o impacto do advento da internet no populismo, visto que este não é só mais um fenômeno que surge pela figura de um líder constituído no povo, mas novas formas de populismo também surgem pelo ativismo algorítmico, organizado em um ambiente virtual (MALY, 2018, 2019 e 2020). A fabricação da categoria povo, nessa forma virtual, estaria sendo feita pelas redes sociais, que, ao desempenharem o papel de líder, disseminariam os discursos responsáveis por estabelecer e articular demandas.

Ao analisar as eleiçóes de Donald Trump nos Estados Unidos em 2016, como exemplo deste populismo digital, Maly (2019) destaca três tipos de ativismo algorítmico: o primeiro é dos chamados click farms, que são pessoas contratadas para "curtir" e "compartilhar" conteúdos em sites de redes sociais, o que contribui para a construçáo de um discurso de apoio popular e para a ativaçáo dos algoritmos das redes sociais, pois, quanto maior a visibilidade, mais eles são distribuídos para outros públicos em potencial; o segundo é das redes de robôs, que são dispositivos acionados nas discussões políticas virtuais para difundir conteúdos dos candidatos, com postagens carregadas de mensagens com valores de diferentes grupos identitários, para que assim seja construído o apoio popular, mesmo que de forma artificial; e o terceiro é de ativistas e celebridades midiáticas, que são pessoas que postam diariamente, pedem retorno e levantam hashtags de apoio aos seus candidatos; além disso, eles estimulam o público a realizar atividades off-line com o intuito de angariar votos, e apropriam-se em muitos casos do discurso populista, ao estimularem a dicotomia "povo versus elite".

Esses discursos populistas corroboram para a maior seletividade de informaçóes, ou seja, para o aumento do acirramento político deflagrado pela polarização de opiniôes políticas com posicionamentos extremos sobre determinados assuntos políticos, criando essa dicotomia entre "nós e eles". A preocupação que surge é de que, quando os indivíduos estão expostos exclusivamente a pessoas ou fatos que reforçam suas crenças pré-existentes, não havendo um ecossistema saudável de ideais concorrentes, a democracia sofre (SUNSTEIN, 2003).

Dentro dos debates sobre polarização política, Yang et al. (2016) distinguem, na literatura, dois tipos de polarização política: (1) a polarização das atitudes ou o reforço de pontos de vista individuais (PRIOR, 2013); (2) a polarização em nível agregado, tais como o aumento da distância entre partidários com preferências políticas opostas (HETHERINGTON e ROUSH, 2013) ou a antipatia que esses partidários sentem um pelo outro (GARRETT et al., 2014). No primeiro tipo de polarização, percebe-se que esta é compreendida como um fenômeno a nível 
individual, que ocorre quando a atitude de um indivíduo se move em direção a uma posição mais extrema (YANG et al., 2016). Enquanto, no segundo tipo, a polarização é em grupo, em que as preferências tendem a se aglomerar em polos ideológicos.

Tem-se na literatura, pensando metodologicamente - independentemente do tipo de polarização -, formas de análise sobre a polarização política, e as mais utilizadas são: a polarização percebida (YANG et al., 2016; GARRET et al., 2014; WESTFALL et al., 2015; SHERMAN, HOGG e MAITNER, 2009) e a polarização afetiva (YANG et al., 2016; IYENGAR, SOOD e LELKES, 2012). Segundo Yang et al. (2016), o crescente foco acadêmico sobre a polarização percebida é motivado pelo reconhecimento de que a percepção em geral tem consequências muito reais para atitudes, cogniçốes e comportamentos do indivíduo. Nesse sentido, quando as pessoas percebem que o eleitorado de massa e os partidos políticos são polarizados, elas pensam que podem adotar preferências políticas mais extremas (AHLER, 2014), porque as pessoas tendem a adotar percepçóes de grupos que afirmam suas identidades sócio-políticas (KATZ, 1960).

Já a polarização afetiva é mensurada pelo sentimento que cada partidário tem dos partidários pertencentes ao grupo contrário, extrapolando o foco de posiçóes políticas para o lado afetivo (IYENGAR, SOOD e LELKES, 2012). Os autores exemplificam a polarização afetiva com base nos Estados Unidos, onde tal polarização tem aumentado ao longo das últimas décadas, pois tanto os republicanos quanto os democratas náo gostam de seus adversários e procedem de forma a extrapolar suas opinióes sobre os traços negativos dos membros do partido adversário. Em suma, os autores afirmam que a polarizaçáo, neste caso, é tanto de atitudes quanto de nível agregado, bem como é formada pela percepção influenciando a afeição.

Em uma direção sinérgica, Yang et al. (2016) trabalham com o pressuposto de que a polarização percebida e a afetiva complementam-se, visto que a percebida trabalha com a percepção das emissóes de conteúdo político, e a afetiva ocorre quando os indivíduos percebem que existem grupos políticos ou sociais diferentes das suas preferências políticas. Ou seja, quando uma pessoa percebe que as posiçôes dos partidos políticos sobre determinadas questôes estão distantes, percebe que existe uma polarizaçáo política, com isso, se a pessoa escolher um dos lados políticos, podem existir grupos políticos dos quais não gosta. A percepção da polarização, então, muda as atitudes dos cidadáos, gerando sentimentos negativos do outro, pois considera que não faz parte do seu grupo. O resultado é a geração da intolerância política e do discurso de ódio. Por isso, discursos populistas podem aumentar esta percepçáo e 
gerar atitudes e comportamentos negativos em relaçáo a determinados assuntos que estão em debate.

Dentro deste arcabouço teórico, podemos partir de duas observaçóes: Donald Trump é um líder populista de direita, e a opinião pública nos Estados Unidos está altamente polarizada. Para além do próprio sistema político, que já é dividido majoritariamente em dois partidos - os democratas e os republicanos - estudos apontam que o país nunca esteve táo dividido e discordando tanto em relaçáo à economia, questão racial, mudanças climáticas, política de segurança pública e saúde, além de muitos outros tópicos (DIMOCK e WIKE, 2020). No entanto, a pandemia do coronavírus demonstrou que, além das diferenças políticas entre republicanos e democratas, estes têm percepçóes completamente opostas em relação aos impactos e preocupaçóes da pandemia.

Nos próximos dois blocos deste artigo, vamos, primeiramente, traçar o discurso político e as posiçóes de Donald Trump sobre o coronavírus e, posteriormente, verificar de que forma isso foi percebido pelos cidadãos estadunidenses, a partir de suas tendências partidárias ${ }^{3}$.

\section{A pandemia do coronavirus nos Estados Unidos e Donald Trump}

O primeiro caso de Covid-19 nos Estados Unidos foi confirmado em 21 de janeiro de 2020. A primeira ação de Donald Trump, em 29 de janeiro, foi banir todos os voos provenientes da China ou de pessoas que houvessem estado no país nos últimos 14 dias, sendo esta ampliada para voos da Europa em março. Além disso, aprovou uma série de medidas emergenciais para auxiliar financeiramente estados, negócios, instituições de saúde, indivíduos e suas famílias. Entretanto, desde o início, o presidente reforçava que a situação no país estaria sob controle e, ao receber críticas sobre sua administração da crise, rebatia com ataques à administraçáo de Obama no surto de H1N1/Influenza (A TIMELINE..., 2020).

Ainda em março, o presidente Donald Trump passou a se referir ao coronavírus, em conferências de imprensa e em seu Twitter, como "o vírus chinês". Seguido por acusaçôes de que seria uma conotação racista, Trump justificou o uso do termo dizendo que não era racista, pois essa era a origem do vírus e ele queria ser preciso. A utilizaçáo foi condenada por autoridades chinesas, uma vez que seria uma

\footnotetext{
${ }^{3}$ Consideramos as respostas da variável "sumário de partido", que classifica os respondentes entre republicanos/tendência a republicano, democrata/tendência a democrata para a nossa análise.
} 
estigmatização da China e de Wuhan, e um despeito à ciência e à OMS. Em contraponto, oficiais americanos acusaram a China de difundir desinformaçáo sobre uma possível origem nos EUA, sem evidências (FORGEY, 2020). Entretanto, após o registro de diversos incidentes de racismo e xenofobia entre comunidades americanas asiáticas desde o início da epidemia, e reforçadas pelas falas de Trump, na semana seguinte o presidente parou de utilizar o termo (SANDLER, 2020).

No mês seguinte, Trump escolheu um novo inimigo político, passando, assim, a atacar a OMS, com a premissa de que suas medidas de combate à epidemia e resposta à China não teriam sido suficientemente agressivas. Tal ataque também representou uma resposta do presidente às críticas da organização sobre sua administração da crise nos EUA. Após ameaça, Trump cortou os fundos do país destinados à organização (TRUMP..., 2020; GAWTHORPE, 2020). Seguindo a mesma lógica, os ataques ao já tradicional inimigo político, a China, tomaram novos contornos: Trump culpa o país pela pandemia e alega que este estaria disposta a fazer qualquer coisa para evitar sua reeleição em novembro (HOLLAND, 2020). Por fim, os governadores democratas também entraram na mira do presidente, com ataques e acusaçóes de que estes estariam atrasando a reabertura econômica como forma de prejudicá-lo nas eleiçôes (MARS, 2020).

Logo após o decreto do estado de emergência pela equipe presidencial, em 15 de março, e o início das medidas de isolamento social (fechamento de escolas, teletrabalho mandatório, proibição de aglomeraçôes), Trump já afirmava que o país voltaria a estar "aberto para negócios" em breve, defendendo que os cidadãos pudessem voltar a trabalhar após o período previsto para as restrições (inicialmente quinze dias), discurso apoiado por canais da mídia conservadora (como a Fox News) e figuras de seu governo. No seu já conhecido estilo para posts de assuntos de aparente urgência, em letras maiúsculas, twittou frases como "NÃO PODEMOS DEIXAR QUE A CURA SEJA PIOR QUE O PRÓPRIO PROBLEMA" (TRUMP, 2020a $)^{4}$. É nesse contexto que os governadores se tornaram alvos dos ataques de Trump, uma vez que os estados têm autonomia para implementar suas próprias medidas, e grande parte optou por maiores restriçóes, ideia contrária a do presidente (ZURCHER, 2020a).

\footnotetext{
${ }^{4}$ Em seu twitter pessoal, @realDonaldTrump tweetou em 23 de março: "WE CANNOT LET THE CURE BE WORSE THAN THE PROBLEM ITSELF. AT THE END OF THE 15 DAY PERIOD, WE WILL MAKE A DECISION AS TO WHICH WAY WE WANT TO GO!".
} 
Como consequência, políticos de direita, setores da mídia e mesmo personalidades públicas começaram a apoiar a realização de protestos contra as medidas de isolamento (GABBATT, 2020). Trump também encorajou abertamente os protestos após anunciar medidas de abertura de seu governo, tendo como alvos centrais estados onde governadores democratas aplicaram medidas estritas, utilizandose de seu Twitter para posts como "LIBEREM MICHIGAN!" e "LIBEREM MINNESOTA!” (TRUMP, 2020b) ${ }^{5}$ (SHEAR e MERVOSH, 2020). Os protestos reuniram de centenas a milhares de pessoas em cidades como Washington e Denver, que protestaram com frases como "o medo é o vírus real" e "acabe com o vírus, não com a economia” (PROTESTS..., 2020). Pesquisas realizadas tanto pelo Pew Research Center como pela Fox News apontam que essa reação ocorre mais por questão de ideologia do que por medo do impacto econômico, e os protestos no país têm emergido centralmente em estados onde há uma intensa divisão partidária (RUSSONELLO, 2020). O movimento surge também como uma forma de unificar vozes de grupos distintos da direita: os conservadores sociais (que veem as restriçóes como ameaça a grupos religiosos), os conservadores fiscais (que se preocupam com a devastação econômica devido às restriçôes a negócios), e os libertários civis (que sustentam que as restriçóes infringem direitos constitucionais) (VOGEL, RUTENBERG e LERER, 2020).

Por parte dos conservadores, foi observada uma constante atribuição da culpa da crise do coronavírus à mídia tradicional, por meio de alegaçóes de que esta visava criar histeria e denegrir a imagem do presidente com o intuito de influenciar as eleiçóes presidenciais ao tentar mostrar que ele não estaria fazendo o suficiente para evitar a propagação do vírus (ZURCHER, 2020b). Os setores conservadores utilizaram-se também do meio digital para incitar revolta contra medidas de restrição, sendo as redes sociais o principal meio de organização desses protestos. Organizaçóes da direita, como a Freedom Works, têm auxiliado a conectar manifestantes e desenvolver websites para eles, além de monitorar semanalmente inquéritos sobre o apoio à abertura em swing districts suburbanos, passando informaçóes para conselheiros da força-tarefa econômica do presidente e aliados conservadores (VOGEL, RUTENBERG e LERER, 2020). O Facebook teve que remover uma série de eventos que convocavam para os protestos. Entretanto, a empresa declarou que só

\footnotetext{
${ }^{5}$ Em seu twitter pessial, @realDonaldTrump tweetou em 17 de abril: "LIBERATE MICHIGAN! LIBERATE MINESSOTA!".
} 
iria retirar os eventos se eles fossem contra as diretrizes definidas pelos governos (CULLIFORD, 2020).

Visando sua reeleição, Trump pretendeu deslocar qualquer culpa sobre a crise para os governadores democratas; assim, seus anúncios apresentam um caráter bipartidário, acirrando a polarizaçáo (SHEAR e MERVOSH, 2020), também reforçada pela mídia conservadora. Trump ataca a mídia, alegando um exagero sobre a crise para prejudicar sua reeleição; ataca estrangeiros, com especial foco na China; especialistas científicos, incluindo profissionais de seu próprio governo; e instituiçóes multilaterais, como a Organização Mundial de Saúde; além de criar conflitos com governadores, especialmente os democratas (CAROTHERS, 2020). A questão tornase mais grave quando observado que as pessoas posicionadas à esquerda do espectro político tendem a acreditar mais em organismos de notícias do que no governo, enquanto a direita acredita mais no governo. Além disso, no país foi observado que políticos geram grande volume de desinformação (NIELSEN et al., 2020).

As fake news também aparecem como um fator de influência da opiniáo pública durante a pandemia (SCHAEFFER, 2020). Muitas partiram até mesmo do próprio presidente, que sugeriu o uso interno de desinfetantes para o combate à Covid-19, e também de cloroquina e hidroxicloroquina, recomendadas diversas vezes por Trump e que podem gerar perigosos efeitos colaterais, o que resultou em um aumento drástico (mais de 46 vezes) na quantidade de prescriçóes apresentadas para a compra dos remédios (ROGERS et al., 2020; GABLER e KELLER, 2020).

Assim, buscamos demonstrar nesta próxima seção que, além de diferentes posicionamentos políticos, os eleitores republicanos e democratas também têm posiçóes e visóes muito diferentes sobre a pandemia do coronavírus e sobre as respostas dadas pelo presidente Donald Trump durante a pandemia.

\section{Polarização política e a opinião pública em torno do coronavirus}

Nesta seção buscamos trazer dados da opinião pública obtidos por meio de bancos de dados do Pew Research Center. Nesta seção vamos visualizar de forma clara, através de cruzamentos inferenciais, as diferenças de percepção entre republicanos e democratas quanto à pandemia do coronavírus e avaliaçáo do papel de Donald Trump como líder político. Como variável dependente usamos a variável de partido/tendência partidária, podendo assim agrupar os respondentes entre republicano/tende a republicano e democrata/tende a democrata. 
Primeiramente, iremos observar as diferentes percepçóes dos republicanos e democratas sobre a importância dada à pandemia, o que nos permite avaliar o que pensam sobre a seriedade da doença.

Gráfico 1 - Percepçôes sobre a pandemia do coronavírus nos Estados Unidos entre republicanos e democratas em setembro de $2020(\%)$

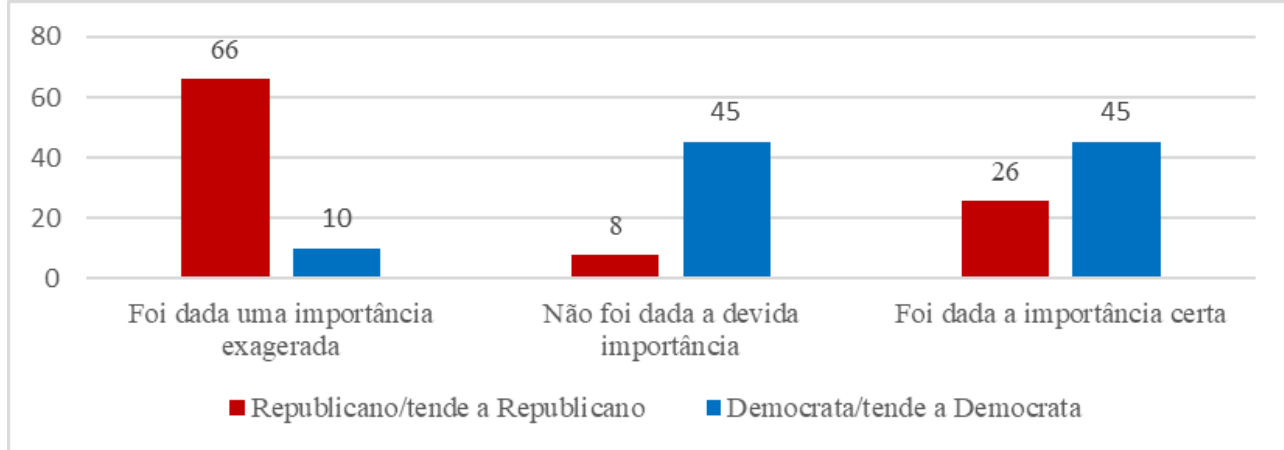

$\mathrm{N}=9039, \mathrm{r}=0,00$

Fonte: Pew Research Center (2020c).

Conforme demonstrado no gráfico acima, percebemos que republicanos e democratas têm uma leitura diferente sobre a importância que foi dada ao surto de Covid-19 no país. Enquanto democratas se mostram majoritariamente divididos entre as afirmaçóes de que náo foi dada a devida importância, e de que foi dada a importância certa - ambos com $45 \%$ das respostas - a maior parte dos republicanos, $66 \%$, afirmam que foi dada uma importância exagerada para a pandemia. Pelas repostas, podemos notar que democratas consideram a pandemia do coronavírus um assunto mais sério, ou mais importante, do que os republicanos. Esses dados foram coletados em setembro deste ano (2020), quando o número de mortes pela Covid-19 nos Estados Unidos já estava próximo de 200 mil. Conforme vimos na seção anterior deste trabalho, Donald Trump, desde o começo, subestimou a seriedade da doença, além de frequentemente acusar a mídia de causar histeria, ideia reforçada pela mídia conservadora.

No Gráfico 2, buscamos mapear as inquietações e preocupaçóes principais dos eleitores de cada um dos partidos. 
Gráfico 2 -Percepção de impacto da pandemia de coronavírus em diferentes setores em março de $2020(\%)$

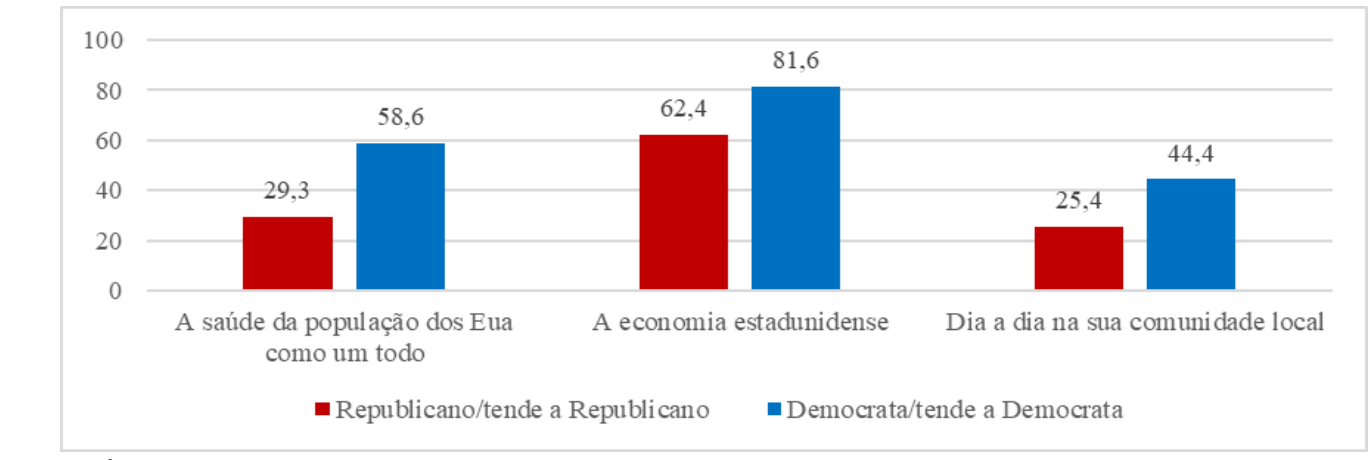

$\mathrm{N}=8675, \mathrm{r}=0,00$

Fonte: Pew Research Center (2020a).

Embora demonstrem diferentes níveis de preocupação, a ordem dos tópicos que mais afligem democratas e republicanos é a mesma. A economia estadunidense é motivo de preocupaçáo para $81,6 \%$ dos democratas e $62,4 \%$ dos republicanos. A seguir, em segundo lugar, indicam a saúde da população do país como um todo, com $58,6 \%$ e 29,3\%, respectivamente. Em terceiro, ambos os grupos partidários mencionam preocupação com a possível ameaça ao dia a dia de suas comunidades locais, com $44,4 \%$ e $25,4 \%$, respectivamente. É interessante ressaltar que, apesar de os discursos de Trump terem forte apelo às perdas econômicas causadas pelas medidas de contenção da pandemia e um tom de acusação de que os Democratas iriam destruir o país com essas medidas, retórica muito vista nos protestos contra tais medidas, percebe-se que na verdade os democratas veem um impacto maior da pandemia na economia do que os republicanos. Esses dados corroboram o que foi apontado por Russonello (2020). Segundo o autor, a adesão aos protestos ocorreu mais por questão ideológica do que propriamente pelo medo do impacto econômico. A resposta sobre o dia a dia na comunidade local corrobora pesquisas (COHEN, 2020) que apontam que democratas acreditam mais do que republicanos que o vírus se espalha muito facilmente ( $48 \%$ vs. $34 \%$, respectivamente), além de estarem mais dispostos a evitar grandes eventos (67\% vs. $49 \%$ ) e espaços públicos (53\% vs. 37\%). 
Gráfico 3 - Acompanhamento de diferentes tópicos de notícias relacionadas à pandemia do coronavírus em setembro de 2020 (\%)

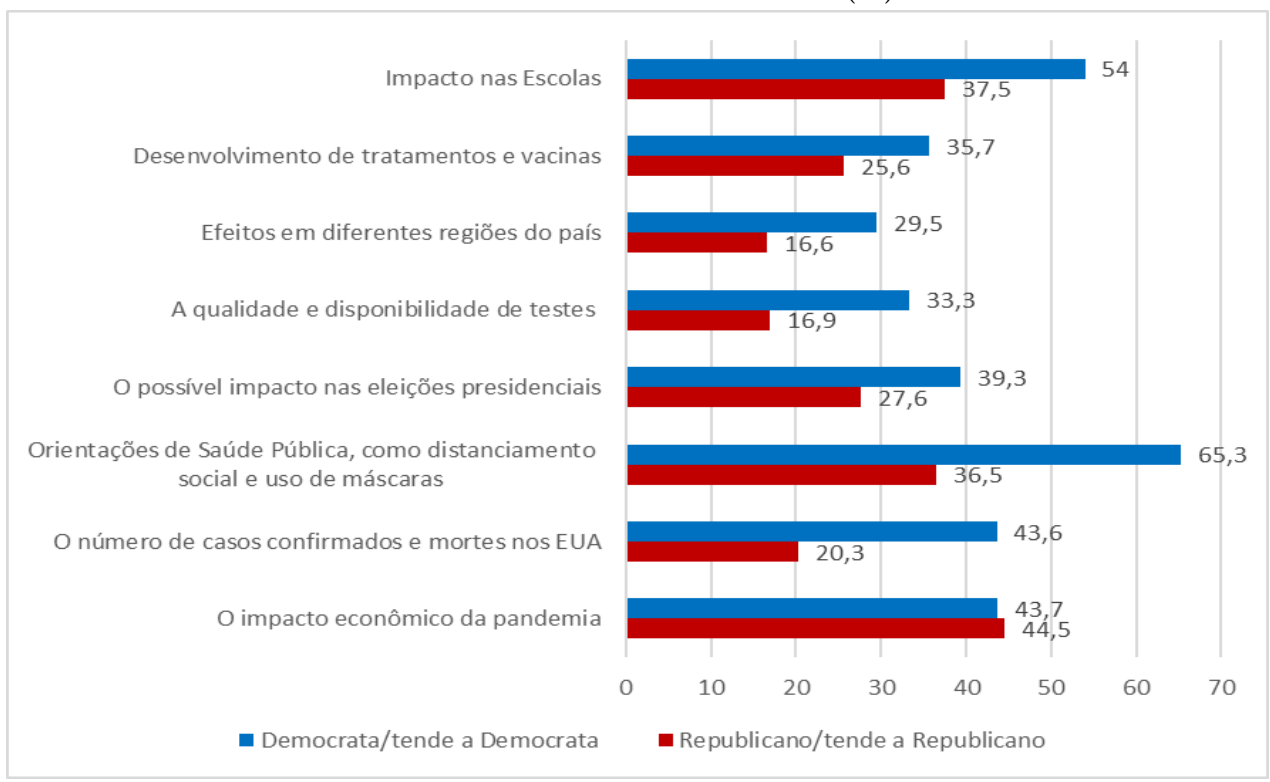

$\mathrm{N}=9039, \mathrm{R}=0,00$

Fonte: Pew Research Center (2020c).

O Gráfico 3 nos permite compreender, através de uma série de temas, como a informação sobre a pandemia é diferentemente consumida por republicanos e democratas. Primeiramente, podemos notar que os democratas buscam mais informação sobre quase todos os temas relacionados à Covid-19, com exceção do impacto econômico, do que os republicanos. Apesar disso, os assuntos de maior interesse em ambos os espectros são as orientações de saúde pública, o impacto nas escolas e o impacto econômico, ainda que em ordens de prioridade distintas.

Podemos peceber também que o impacto econômico é o tema que encontra mais paridade entre os dois polos, que buscam informação sobre quase na mesma quantidade. Em contraponto, os tópicos com maior disparidade de busca por informação são as orientaçóes de saúde, com $28,8 \%$ de diferença, e as estatísticas da doença, com $23,3 \%$ de diferença, ambos com maior interesse por parte dos democratas. A diferença pode ser atribuída à forma como cada grupo consome informaçóes, uma vez que republicanos tendem a ouvir mais ao presidente, que durante toda a pandemia foi na direção contrária da ciência e das referências em saúde, como a própria OMS. Entretanto, iremos agora aprofundar essa questão com o Gráfico 4, que mostra o modo como cada grupo se informa: 
Gráfico 4 - Principal fonte de informação sobre a pandemia para republicanos e democratas em abril de $2020(\%)$

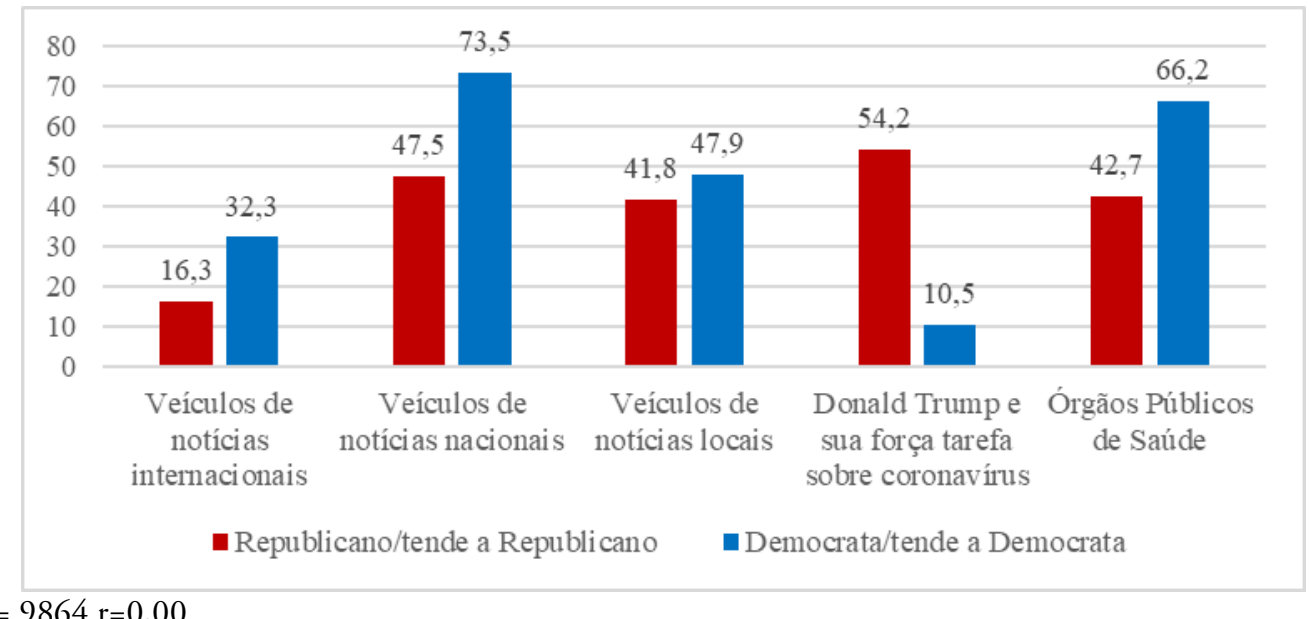

$\mathrm{n}=9864 \mathrm{r}=0,00$

Fonte: Pew Research Center (2020b).

Neste gráfico podemos observar as principais fontes de informação que republicanos e democratas utilizam para se atualizar sobre o coronavírus. Novamente, os democratas buscam mais informaçóes sobre o coronavírus em todas as categorias, salvo quando a fonte é a do presidente republicano Donald Trump e a força tarefa do coronavírus comandada pelo vice-presidente Mike Pence. A ordem de preferência dos democratas para busca de informação é $73,5 \%$ em veículos de notícias nacionais, 66,2\% em órgãos públicos de saúde, 47,9\% em veículos de notícias locais, 32,3\% em veículos de notícias internacionais e apenas $10,5 \%$ na força tarefa de Trump. Inversamente, os republicanos concentram a sua busca de informações na força tarefa de Donald Trump, com 54,2\%, havendo um equilíbrio na casa dos $40 \%$ na busca de informação em veículos nacionais $(47,5 \%)$, locais $(41,8 \%)$ e em órgãos públicos de saúde (42,7\%). Apenas 16,3\% dos republicanos buscam informações sobre a pandemia em veículos de notícias internacionais.

Esses dados não apenas refletem fortemente em como republicanos e democratas avaliam os esforços do governo em combater a pandemia do coronavírus. Embora a maioria dos estadunidenses concordem que o governo náo controlou a pandemia táo bem como poderia (61\%), quando avaliamos essa questáo separadamente entre republicanos e democratas, conforme o Gráfico 5, encontramos perceçóes completamente diferentes sobre a pandemia. 
Gráfico 5 - Avaliações sobre a administração da pandemia entre republicanos e democratas em setembro de 2020 (\%)

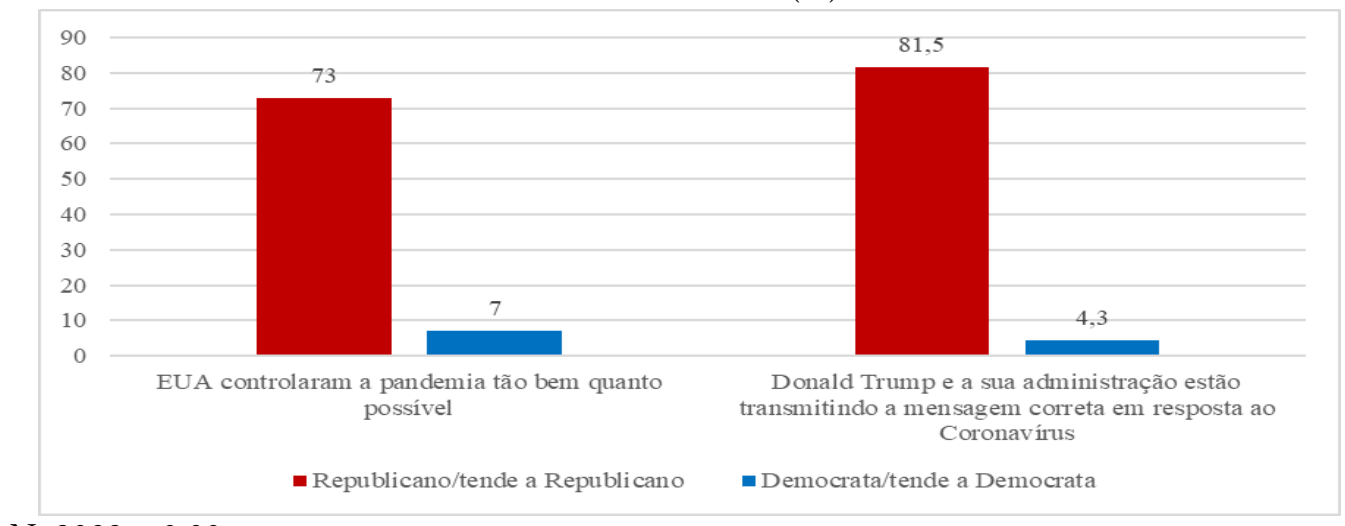

$\mathrm{N}=9039 \mathrm{r}=0,00$

Fonte: Pew Research Center (2020c).

As taxas de respostas são completamente opostas quando analisadas separadamente. Ao passo que $73 \%$ dos republicanos pensam que os Estados Unidos controlaram a pandemia tão bem quanto possível, apenas $7 \%$ dos democratas indicaram essa resposta. Nesse mesmo recorte, olhando de forma mais direta para Donald Trump e a sua administração, $81,5 \%$ dos republicanos afirmam que a gestão do presidente está transmitindo a mensagem correta em resposta ao coronavírus, ao passo que, para os democratas, esse número é de apenas 4,3\%.

Estes dados têm implicaçóes reais para o controle do coronavírus, uma vez que os republicanos, por não julgarem a situação com a devida seriedade, são menos propensos a usar máscaras e mais propensos a participar de aglomeraçóes. Uma pesquisa realizada pelo Galup em junho e julho mostrou que $96 \%$ dos democratas usam máscara sempre ou quase sempre, número que é de apenas $46 \%$ entre republicanos (LAW, 2020). A primeira vez que o presidente Donald Trump foi visto usando máscara de proteção em público foi em 12 de julho. Além disso, o presidente fez várias falas questionando a eficácia das máscaras e sugerindo que o uso delas deveria ser voluntário, indo contra as recomendaçóes da própria força-tarefa do governo.

Como mencionado anteriormente, Donald Trump questionou as medidas de isolamento social impostas por governadores democratas, posicionando-as como uma tentativa de trazer dano à economia no seu governo como presidente e prejudicá-lo na corrida eleitoral de novembro. Os diferentes índices de confiança nas informaçóes veiculadas por diferentes setores, de forma geral, parece refletir os frequentes ataques 
do presidente aos governadores e à mídia quando vemos os números separados entre republicanos e democratas, conforme demonstrado no Gráfico 6.

Gráfico 6 - Quanto acha que essas fontes transmitem informações corretas sobre o coronavírus: sempre/quase sempre em setembro de 2020 (\%)

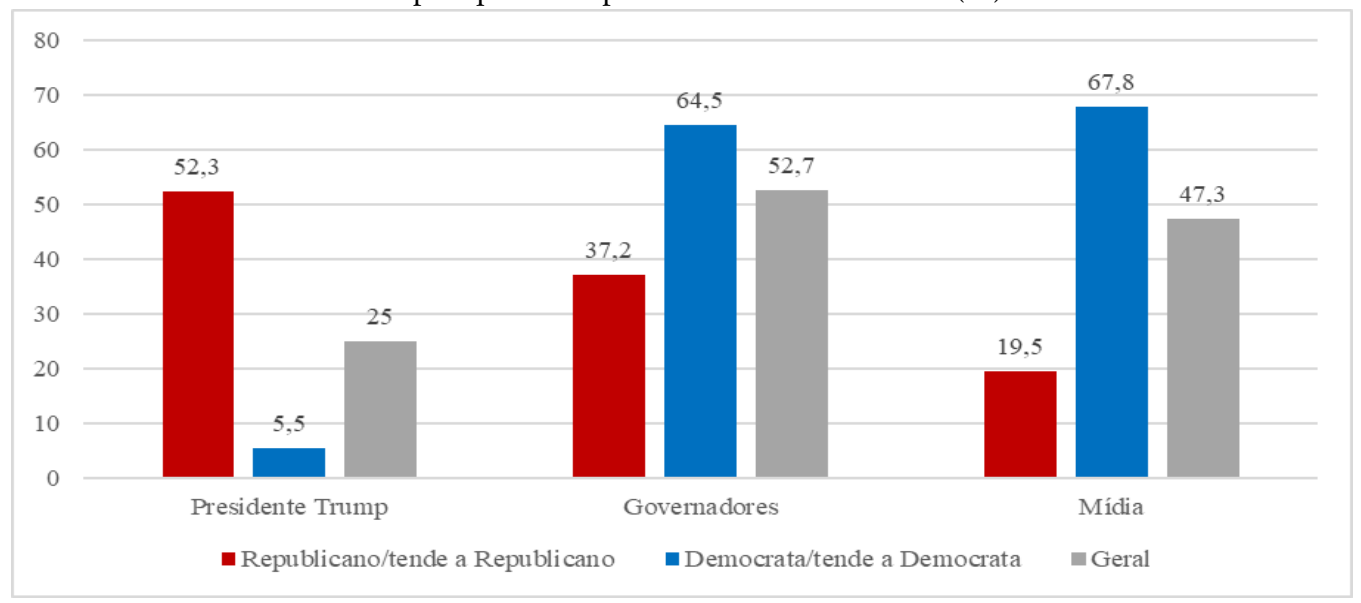

$\mathrm{N}=9039, \mathrm{r}=0,00$

Fonte: Pew Research Center (2020c).

Avaliando os dados acima sem levar em conta o partido/tendência partidária, podemos observar que apenas $25 \%$ dos respondentes entendem que o presidente Trump dá informaçóes corretas, sempre ou quase sempre, sobre o coronavírus. Destes, $52,7 \%$ afirmam o mesmo sobre os govenadores e $47,3 \%$ sobre a mídia. De forma geral, podemos identificar um nível de ceticismo e baixa confiança nas informaçóes repassadas por essas fontes. No entanto, ao separarmos por partido, verificamos, novamente, uma grande divisão de opinióes entre republicanos e democratas. Ao passo que apenas 5,5\% dos democratas levam a sério as informaçóes sobre a pandemia passadas por Donald Trump, 52,3\% dos republicanos veem nele a fonte mais certeira de informação.

Embora a confiança na veracidade das informações divulgadas pelos governadores seja a que apresentou menor variaçáo entre os dois polos políticos, podemos observar um maior suporte dos democratas (64,5\%), independentemente de o governador ser democrata ou republicano. A mídia também se mostra como um dos maiores divisores de opinião entre republicanos (19,5\%) e democratas $(67,8 \%)$, narrativa incentivada pelo próprio presidente, que inúmeras vezes acusou a mídia de propagar notícias falsas e provocar histeria durante a pandemia. 


\section{Considerações finais}

Pela literatura revisada, o governo de Trump é caracterizado pelo populismo, com discursos marcados pela intolerância, pela criaçáo de um inimigo e pelo reforço do nacionalismo e capitalismo (MUDDE e ROVIRA KALTWASSER, 2017; HAWKINS e ROVIRA KALTWASSER, 2019; NORRIS e INGLEHART, 2019, MALY, 2019 e 2020). Além disso, na literatura também se destaca a existência de uma polarizaçáo política na sociedade norte americana (IYENGAR, SOOD e LELKES, 2012). A partir disso, pensando no momento atual de crise vivenciado pela pandemia, partiu-se do objetivo de verificar a formação da opiniáo pública sobre a Covid-19 nos EUA frente aos posicionamentos de Donald Trump, especialmente à luz da polarização política encontrada nos EUA, entre republicanos e democratas, que vai muito além do aspecto político.

Conforme vimos, Donald Trump utilizou-se de discursos em tom bipartidário que acirraram a polarização (SHEAR e MERVOSH, 2020) entre republicanos e democratas. Tais discursos tinham alguns temas centrais, como os ataques à mídia e aos governadores democratas, a culpabilização da China e a contraposição a organizaçóes científicas (CAROTHERS, 2020). Nas análises dos dados, percebemos que as visóes dos estadunidenses sobre tópicos como informação sobre a pandemia, avaliação da administração no controle da crise e seus impactos no país encontram-se extremamente polarizadas entre os dois extremos políticos do país, republicanos e democratas. Não fazemos aqui uma relação direta e exclusiva entre os discursos de Trump e a polarização, pois as análises não nos permitem isso, mas destacamos que a opiniáo pública nos EUA está polarizada: os republicanos e os que tendem ao Partido Republicano apresentam opinióes similares aos discursos do presidente, enquanto os democratas e que tendem ao Partido Democratas divergem significativamente desses posicionamentos apresentados nos discursos de Trump.

A polarizaçáo política não é uma novidade nos EUA, Pildes (2011) destaca que esta se agravou significativamente com as reformas encetadas na década de 1960. Além disso, a divisão partidária, entre republicanos e democratas, presente no cenário político norte-americano vem se agravando e impactando o colégio eleitoral (GROSSMANN e HOPKINS, 2015), visto que, nas últimas duas décadas, duas eleiçóes presidenciais - 2000 e 2016 - tiveram um vencedor pelo voto popular que não conquistou o colégio eleitoral. Mais um exemplo é o colapso, em 2012, nas negociaçóes entre o presidente Obama e o líder republicano John Boehner, o que ilustrou bem a incapacidade de gerir as diferenças partidárias. 
Porém, desde 2016, com a vitória de Donald Trump, há uma percepção mais evidente da polarizaçáo política, assim como do impacto que discursos populistas e fake news podem ter na deslegitimação do sistema político de uma nação. No caso da pandemia do coronavírus, se evidencia o extremo em que as consequências dessa retórica podem chegar, uma vez que, ao se negar os fatos e a própria ciência, vidas se perdem. Isso se reflete nos altos números de infectados e mortos nos EUA nesta pandemia, que podem ser um reflexo direto dos discursos de Trump, que minimizam a seriedade da doença, descreditam a ciência e que buscam dividir a população entre o "nós" e o "inimigo". Da mesma forma, esses diferentes comportamentos entre democratas e republicanos também impactaram o próprio rito eleitoral no país.

As eleiçôes estadunidenses ocorreram no dia 3 de novembro; no entanto, em função da pandemia, os democratas optaram por encorajar seus eleitores a votarem pelo correio, diferentemente dos republicanos, que, seguindo orientaçóes do presidente, optaram por votar no dia. Muitos estados norte-americanos têm a política de apenas contar os votos do correio após o fechamento da eleiçáo presidencial, de forma que, no início da apuraçáo, se mostraram estados vermelhos (republicanos) que acabaram tornando-se azuis (democratas) à medida que os votos do correio iam sendo contabilizados.

Sem urnas eletrônicas, a contagem dos votos nos Estados Unidos costuma tomar alguns dias para se desenhar, os quais foram marcados por um clima de tensão enquanto Donald Trump entrou com recursos pedindo que paralisassem as contagens nos chamados "Estados pêndulos", decisivos para essa eleição. O resultado das urnas veio no sábado, dia 7 de novembro, quando a chapa Biden-Harris conquistou o mínimo de 270 votos no colégio eleitoral, impossibilitando que Donald Trump alcançasse um número maior de votos. Ao fim das apuraçôes, Biden-Harris conquistaram 306 votos nos colégios eleitorais, além de uma maioria de eleitores (foram contabilizados 80.025 .936 votos, $51,1 \%$ do eleitorado). Porém, mesmo com a contagem de votos encerrada e sem mérito em suas explanações sobre fraude eleitoral, Donald Trump levou mais de 20 dias para aceitar a derrota nas urnas, e, sem um pronunciamento oficial, apenas autorizou que a equipe de transição democrata começasse seus trabalhos no dia 24 de novembro (ELEIÇÕES..., 2020).

Nesse sentido, no caso da pandemia da Covid-19, assim como vimos que os discursos de um líder impactam a forma como os cidadãos percebem diversos aspectos da sociedade, igualmente a postura de Donald Trump de não reconhecer o resultado das urnas, insinuando que houve fraude eleitoral, não só põe em jogo a 
estabilidade e confiabilidade da democracia mais antiga do mundo, como também é capaz de reforçar e legitimar setores extremistas da sociedade. Pesquisa recente divulgada pelo The Economist aponta que 86\% dos eleitores de Trump acreditam que a vitória de Joe Biden seja ilegítima (THE REPUBLICAN PARTY..., 2020). Assim, se a polarização do país já se mostrava aparente durante a pandemia, a eleição de novembro de 2020 mostrou com clareza como o país se encontra dividido e o grande desafio que Joe Biden enfrentará como presidente para reunificar o país.

- Jennifer Azambuja de Morais é Doutora em Ciência Politica, pela Universidade Federal do Rio Grande do Sul (UFRGS). É Professora do Programa de Pós-Graduação em Ciência Política da UFRGS e Pesquisadora do Núcleo de Pesquisa sobre a América Latina (NUPESAL/UFRGS). E-mail: jennifer.amorais@gmail.com.

Andressa Liegi Vieira Costa é Mestra em Ciência Política, pela Universidade de Lisboa (ISCSP/ULisboa). Pesquisadora do NUPESAL/UFRGS e do projeto Manchetômetro do Laboratório de Estudos de Mídia e Esfera Pública (LEMEP/UERJ). E-mail: andressaliegi@ hotmail.com.

- Ana Julia Bonzanini Bernardi é Doutoranda e Mestra em Ciência Politica, pela UFRGS. Pesquisadora do NUPESAL/UFRGS. E-mail: ana.bernardi@ ufrgs.br.

\section{Referências}

AHLER, Douglas. Self-fulfilling misperceptions of public polarization. The Journal of Politics, v. 76, n. 3, p. 607-620, 2014. Disponível em: <http://www.dougahler.com/uploads/2/4/6/9/24697799/ ahler_sfmpp.pdf>. Acesso em 07 nov. 2020.

A TIMELINE of the Trump administration's coronavirus actions. Al Jazeera, Apr. 23, 2020. Disponível em: <https://www.aljazeera.com/news/2020/04/timeline-trump-administrationcoronavirus-actions-200414131306831.html>. Acesso em: 15 maio 2020.

BONIKOWSKI, Bart. Trump's Populism: The Mobilization of Nationalist Cleavages and the Future of U.S. Democracy. In: WEYLAND, Kurt; MADRID, Raúl (Eds.). When Democracy Trumps Populism: Lessons from Europe \& Latin America. New York: Cambridge University Press, 2019. p. 110-131. 
CAROTHERS, Thomas. The United States: Presidential Leadership, Polarization, and the Coronavirus. Carnegie Endowment for International Peace, Apr. 28, 2020. Disponível em: <https://carnegieendowment.org/2020/04/28/united-states-presidential-leadership-polarization-andcoronavirus-pub-81643>. Acesso em: 30 abr. 2020.

COHEN, John. Axios/SurveyMonkey poll: perceptions of coronavirus. Mar. 2020. Disponível em: <https:/www.surveymonkey.com/curiosity/axios-coronavirus-perception/>. Acesso em: 15 maio 2020.

COSTA, Ligia Maria; MERCHAN-HAMANN, Edgar. Pandemias de influenza e a estrutura sanitária brasileira: breve histórico e caracterizaçáo dos cenários. Revista Pan-Amaz Saude, v. 7, n. 1, p. 11-25, 2016.

CULLIFORD, Elizabeth. Facebook removes anti-quarantine protest events in some U.S. states. Reuters, Apr. 20, 2020. Disponível em: <https://www.reuters.com/article/us-health-coronavirus-usafacebook/facebook-removes-anti-quarantine-protest-events-in-some-us-states-idUSKBN2222QK>.

Acesso em: 15 maio 2020.

DIMOCK, Michael; WIKE, Richard. America is exceptional in the nature of its political divide. Pew Research Center, Nov. 13, 2020. Disponível em: <https:/www.pewresearch.org/facttank/2020/11/13/america-is-exceptional-in-the-nature-of-its-political-divide/>. Acesso em: 18 nov. 2020.

DI TELLA, Torcuato. Populismo y reformismo. In: GERMANI, Gino; DI TELLA, Torcuato; IANNI, Octavio. Populismo y contradicciones de clase en Latinoamerica. México: Era, 1973. p. 3882.

ELEIÇÓES nos EUA: Trump aceita início de transiçáo para governo Biden nos EU. BBC News Brasil, 23 nov. 2020. Disponível em: <https://www.bbc.com/portuguese/internacional-55053496>. Acesso em: 2 dez. 2020.

FORGEY, Quint. Trump on 'Chinese virus' label: 'It's not racist at all'. Politico, 18 mar. 2020. Disponível em: <https:/www.politico.com/news/2020/03/18/trump-pandemic-drumbeatcoronavirus-135392>. Acesso em: 20 abr. 2020.

GABBATT, Adam. Protests against US stay-at-home orders gain support from rightwing figures. The Guardian, Apr. 16, 2020. Disponível em: <https://www.theguardian.com/world/2020/apr/16/ michigan-protest-coronavirus-rightwing-support>. Acesso em: 15 maio 2020.

GABLER, Ellen; KELLER, Michael H. Prescriptions Surged as Trump Praised Drugs in Coronavirus Fight. The New York Times, Apr. 25, 2020. Disponível em: <https:/www.nytimes.com/2020/04/25/us/coronavirus-trump-chloroquinehydroxychloroquine.html>. Acesso em: 3 dez. 2020.

GARRETT, Kelly et al. Implications of proand counterattitudinal information exposure for affective polarization. Human Communication Research, v. 40, n. 3, p. 309-332, 2014.

GAWTHORPE, Andrew. Trump's decision to cut WHO funding is an act of international vandalism. The Guardian, Apr. 15, 2020. Disponível em: <https://www.theguardian.com/ commentisfree/2020/apr/15/trump-decision-cut-who-funding-international-vandalismcoronavirus>. Acesso em: 15 maio 2020. 
GERMANI, Gino. Democracia representativa y clases populares. In: GERMANI, Gino; DI TELLA, Torcuato; IANNI, Octavio. Populismo y contradicciones de clase en Latinoamerica. México: Era, 1973. p. 12-37.

GOLLWITZER, Anton et al. Partisan differences in physical distancing are linked to health outcomes during the COVID-19 pandemic. Nature Human Behaviour, v. 4, p. 1186-1197, Nov. 2, 2020. Disponível em: <http://dx.doi.org/10.1038/s41562-020-00977-7>. Acesso em: 19 nov. 2020.

GROSSMANN, Matt; HOPKINS, David. Ideological Republicans and Group Interest Democrats: The Asymmetry of American Party Politics. Perspectives on Politics, v. 13, n. 1, p.119-139, 2015.

HAWKINS, Kirk A.; ROVIRA KALTWASSER, Cristóbal. Introduction: the ideational approach. In: HAWKINS, Kirk A. et al. (Eds.). The ideational approach to populism: concept, theory, and method. New York: Routledge, 2019. p. 1-41.

HETHERINGTON, March; ROUSH, Carolyn. Perceiving the other side: Toward a new understanding of mass polarization. In: ANNUAL CONFERENCE OF THE MIDWEST POLITICAL SCIENCE ASSOCIATION, 61., 2013, Chicago. Proceedings... Chicago, 2013.

HOLLAND, Steve. Exclusive: Trump says China wants him to lose his re-election bid. Reuters, Apr. 30, 2020. Disponível em: <https://www.reuters.com/article/us-usa-trump-china-exclusive/exclusivetrump-says-china-wants-him-to-lose-his-bid-for-re-election-idUSKBN22C01F>. Acesso em: 15 maio 2020.

IANNI, Octavio. Populismo y relaciones de clase. In: GERMANI, Gino.; DI TELLA, Torcuato.; IANNI, Octavio. Populismo y contradicciones de clase en Latinoamerica. México: Era, 1973. p. 83150.

IYENGAR, Shanto; SOOD, Gaurav; LELKES, Yphtach. Affect, not ideology: a social identity perspective on polarization. Public Opinion Research, v. 76, n. 3, p. 405-431, 2012.

JAGERS, Jan; WALGRAVE, Stefaan. Populism as political communication style: An empirical study of political parties' discourse in Belgium. European Journal of Political Research, v. 46, p. 319-345, 2007.

KATZ, Daniel. The functional approach to the study of attitude. Public Opinion Quarterly, v. 24, p. 163-204, 1960. Disponível em: <http://psych.colorado.edu/-chlo0473/teaching/2015_F/ articles/Katz_1960.pdf>. Acesso em: 3 out. 2020.

LACLAU, Ernesto. A razão populista. São Paulo: Três Estrelas, 2005.

LAW, Tara. Democrats and Republicans aren't watching the same pandemic. Time, Oct. 9, 2020. Disponível em: <https://time.com/5898231/republicans-democrats-coronavirus-news/>. Acesso em: 19 nov. 2020.

LIMA, Diego; LOPES, Maria Antonieta; BRITO, Ana Maria. Social media: friend or for in the COVID-19 pandemic? Clinics, v. 75, e1953, 2020.

MALY, Ico. Algorithmic populism and the datafication and gamification of the people by flemish interest in Belgium. Trab. Ling. Aplic., v. 59, n. 1, p. 444-468, jan./abr. 2020.

MALY, Ico. Algorithmic populism and algorithmic activism. Diggit Magazine, Nov. 26, 2019. Disponível em: <https://www.diggitmagazine.com/articles/algorithmic-populism-activism>. Acesso em: 05 dez. 2020.

MALY, Ico. Populism as a mediatized communicative relation: The birth of algorithmic populism. Tilburg Papers in Culture Studies, n. 213, 2018. Disponível em: <https:/www.researchgate.net/ 
publication/328095323_Populism_as_a_mediatized_communicative_relation_The_birth_of_algorit hmic_populism>. Acesso em: 05 dez. 2020.

MARS, Amanda. Trump acusa governadores democratas de atrasarem reabertura para prejudicá-lo politicamente. El País, 12 maio 2020. Disponível em: <https://brasil.elpais.com/internacional/202005-12/trump-acusa-governadores-democratas-de-atrasarem-reabertura-para-prejudica-lopoliticamente.html?fbclid=IwAR053OoXatV8W2ZJvp6D1KSKdrrjYFrYwMr7x70XkqmiFMZywB5-3027xA>. Acesso em: 22 maio 2020.

MAZZOLENI, Gianpietro. The media and the growth of neo-populism in contemporary democracies. In: MAZZOLENI, Gianpietro; STEWART, Julianne; HORSFIELD, Bruce (Eds.). The media and neo-populism: A contemporary comparative analysis. Westport, CT: Praeger, 2003. p. 1-20.

MUDDE, Cas. Populist Radical Right Parties in Europe. Cambridge/New York: Cambridge University Press, 2007.

MUDDE, Cas; ROVIRA KALTWASSER, Cristóbal. Populism: a very short introduction. Oxford: Oxford University Press, 2017.

NIELSEN, Rasmus Klein et al. Navigating the 'infodemic': how people in six countries access and rate news and information about coronavirus. Reuters Institute, Apr. 15, 2020. Disponível em: <https://reutersinstitute.politics.ox.ac.uk/infodemic-how-people-six-countries-access-and-rate-newsand-information-about-coronavirus >. Acesso em: 8 maio 2020.

NORRIS, Pippa; INGLEHART, Ronald. Cultural backlash: Trump, Brexit, and authoritarian populism. Cambridge: Cambridge University Press, 2019.

ORGANIZAÇÃO MUNDIAL DE SAÚDE (OMS). Situaçâo do coronavírus por país em 12 de novembro de 2020. 2020. Disponível em: <https://covid19.who.int/table>. Acesso em: 12 nov. 2020.

PEW RESEARCH CENTER. Coronavirus Survey March 2020. (Wave 63.5 Coronavirus Survey: March 10-16, 2020, N=8,914). 2020a. Disponível em: <https:/www.journalism.org/dataset/ election-news-pathways-march-2020-survey/>. Acesso em: 19 nov. 2020.

PEW RESEARCH CENTER. American Trends Panel April 2020. (Pathways \& Trust in Media Survey April 20-26, 2020, N=10,139). 2020b. Disponível em: <https:/www.journalism.org/dataset/covid-19-late-april-2020/>. Acesso em: 19 nov. 2020.

PEW RESEARCH CENTER. American News Pathways September 2020 Survey. (Wave 73 Pathways \& Social Media Survey: August 31-September 7, 2020. N=9,220). 2020c. Disponível em: $<$ https://www.journalism.org/dataset/american-news-pathways-september-2020-survey/>. Acesso em: 19 nov. 2020.

PHILIP, George; PANIZZA, Francisco. The triumph of politics: the return of the left in Venezuela, Bolivia, Ecuador. Cambridge, UK: Polity, 2011.

PILDES, Richard. Why the Center Does Not Hold: The Causes of Hyperpolarized Democracy in America. California Law Review, v. 99, n. 2, p.273-334, 2011.

PRIOR, Markus. Media and Political Polarization. Annual Review of Political Science, v. 16, p. 101127, 2013. Disponível em: <https://www.princeton.edu/ $\sim$ mprior/Prior\%20MediaPolarization.pdf>. Acesso em: 20 out. 2020. 
PROTESTS in Washington, Colorado against US coronavirus curbs. Al Jazeera, Apr. 20, 2020. Disponível em: <https://www.aljazeera.com/news/2020/04/protests-washington-coloradocoronavirus-curbs-200420030414300.html>. Acesso em: 15 maio 2020.

REZENDE, Joffre Marcondes de. À sombra do plátano: crônicas de história da medicina. In: REZENDE, Joffre Marcondes de. As grandes epidemias da história. São Paulo: Editora Unifesp, 2009. p. 73-82.

ROGERS, Katie et al. Trump's Suggestion That Disinfectants Could Be Used to Treat Coronavirus Prompts Aggressive Pushback. The New York Times, Apr. 24, 2020. Disponível em: $<$ https://www.nytimes.com/2020/04/24/us/politics/trump-inject-disinfectant-bleachcoronavirus.html>. Acesso em: 3 dez. 2020.

RUSSONELLO, Giovanni. What's Driving the Right-Wing Protesters Fighting the Quarantine? The New York Times, Apr. 17, 2020. Disponível em: <https://www.nytimes.com/2020/04/17/us/ politics/poll-watch-quarantine-protesters.html>. Acesso em: 30 abr. 2020.

SANDLER, Rachel. Trump Abruptly Stops Calling Coronavirus 'Chinese Virus' At Daily Press Briefing. Forbes, Mar. 23, 2020. Disponível em: <https://www.forbes.com/sites/rachelsandler/2020/03/23/trump-abruptly-stops-calling-coronaviruschinese-virus-at-daily-press-briefing/\#2d1548ea47ad>. Acesso em: 25 mar. 2020.

SCHAEFFER, Katherine. Nearly three-in-ten Americans believe COVID-19 was made in a lab. Pew Research Center, Apr. 8, 2020. Disponível em: <https://www.pewresearch.org/fact$\operatorname{tank} / 2020 / 04 / 08 /$ nearly-three-in-ten-americans-believe-covid-19-was-made-in-a-lab/>. Acesso em: 3 dez. 2020.

SHEAR, Michael; MERVOSH, Sarah. Trump Encourages Protest Against Governors Who Have Imposed Virus Restrictions. The New York Times, Apr. 17, 2020. Disponível em: <https://www.nytimes.com/2020/04/17/us/politics/trump-coronavirus-governors.html>. Acesso em: 15 maio 2020.

SHERMAN, David; HOGG, Michael; MAITNER, Angela. Perceived Polarization: Reconciling Ingroup and Intergroup Perceptions Under Uncertainty. Group Processes \& Intergroup Relations, v. 12, n. 1, p. 95-109, 2009. Disponível em <http://thirdworld.nl/order/ 5cac317a23e913412f1ace0455b226f9f04cb820>. Acesso em: 22 out. 2020.

STAVRAKAKIS, Yannis; KATSAMBEKIS, Giorgos. Left-wing populism in the European periphery: The case of SYRIZA. Journal of Political Ideologies, v. 19, n. 2, p. 119-142, 2014.

SUNSTEIN, Cass. República.com: Internet, democracia y libertad. Barcelona: Paidós, 2003.

TAGGART, Paul. Populism and the pathology of representative politics. In: MENY, Yves; SUREL, Yves (Eds.). Democracies and the populist challenge. New York: Palgrave, 2002. p. 62-80.

TAKAMI, Eduardo; FUKS, Mario. Populism in Brazil's 2018 general elections: an analysis of Bolsonaro's campaign speeches. Lua Nova, v. 109, p. 103-127, 2020.

THE REPUBLICAN PARTY and Donald Trump's alternative election fantasy. The Economist, Nov. 14, 2020. Disponível em: <https:/www.economist.com/united-states/2020/11/14/the-republicanparty-and-donald-trumps-alternative-election-fantasy>. Acesso em: 25 nov. 2020.

TRUMP attacks WHO and Ousts Watchdog for Pandemic Fund. The New York Times, Apr. 7 , 2020. Disponível em: <https://www.nytimes.com/2020/04/07/world/coronavirus-updates-newslive.html\#link-5e3b2c82>. Acesso em: 15 maio 2020. 
TRUMP, Donald. WE CANNOT LET THE CURE BE WORSE THAN THE PROBLEM ITSELF. AT THE END OF THE 15 DAY PERIOD, WE WILL MAKE A DECISION AS TO WHICH WAY WE WANT TO GO! Washington, DC, Mar. 23, 2020a. Twitter: @realDonaldTrump. Disponível em: <https://twitter.com/realDonaldTrump/status/124193528 5916782593>. Acesso em: 23 set. 2020.

TRUMP, Donald. LIBERATE MICHIGAN! LIBERATE MINNESOTA! Washington, DC, Apr. 17, 2020b. Twitter: @realDonaldTrump. Disponível em: < https://twitter.com/realdonaldtrump/status/1251169217531056130> Acesso em: 11 nov. 2020.

UNESCO. Journalism, press freedom and COVID-19. Material de campanha da UNESCO para o Dia Mundial da Liberdade de Imprensa de 2020. 2020. Disponível em: $<$ https://en.unesco.org/sites/default/files/unesco_covid_brief_en.pdf>. Acesso em: 18 set. 2020.

VAN KESSEL, Stijn. Explaining the electoral performance of populist parties: The Netherlands as a case study. Perspectives on European Politics and Society, v. 12, n. 1, p. 68-88, 2011.

VOGEL, Kenneth; RUTENBERG, Jim; LERER, Lisa. The Quiet Hand of Conservative Groups in the Anti-Lockdown Protests. The New York Times, Apr. 21, 2020. Disponível em: <https:/www.nytimes.com/2020/04/21/us/politics/coronavirus-protests-trump.html>. Acesso em: 16 maio 2020.

WEFFORT, Francisco. O Populismo na Política Brasileira. In: WEFFORT, Francisco. O Populismo na Política Brasileira. Rio de Janeiro: Paz e Terra, 1978. p. 61-78.

WESTFALL, Jacob et al. Perceiving Political Polarization in the United States: Party Identity Strength and Attitude Extremity Exacerbate the Perceived Partisan Divide. Perspectives on Psychological Science, v. 10, n. 2, p. 145-158, 2015.

YANG, Jung et al. Why Are "Others" So Polarized? Perceived Political Polarization and Media Use in 10 Countries. Journal of Computer-mediated Communication, v. 21, p. 349-367, 2016.

ZURCHER, Anthony. Coronavirus: Trump wants US open for business amid pandemic. BBC News, Mar. 24, 2020a. Disponível em: <https://www.bbc.com/news/world-us-canada-52009108>. Acesso em: 30 mar. 2020.

ZURCHER, Anthony. Coronavirus: Who Trump supporters blame for virus 'hysteria'. BBC News, Mar. 11, 2020b. Disponível em: <https://www.bbc.com/news/world-us-canada-51840227>. Acesso em: 20 mar. 2020.

Texto recebido em 12 de novembro de 2020. Aprovado em 22 de novembro de 2020. 